Article

\title{
Strategies for Promoting Green Building Technologies Adoption in the Construction Industry-An International Study
}

\author{
Albert Ping Chuen Chan ${ }^{1}$, Amos Darko ${ }^{1, *}$ and Ernest Effah Ameyaw ${ }^{2}$ \\ 1 Department of Building and Real Estate, The Hong Kong Polytechnic University, 11 Yuk Choi Rd, \\ Hung Hom, Kowloon, Hong Kong, China; albert.chan@polyu.edu.hk \\ 2 School of Engineering, Environment and Computing, Coventry University, Coventry CV3 1NZ, UK; \\ ernest.ameyaw@connect.polyu.hk \\ * Correspondence: amos.darko@connect.polyu.hk; Tel.: +85-25-5477127
}

Academic Editor: Tan Yigitcanlar

Received: 25 May 2017; Accepted: 2 June 2017; Published: 6 June 2017

\begin{abstract}
Because green building technologies (GBTs) adoption is a promising way of ameliorating the sustainability performance of buildings, GBTs are receiving increased interest in the global construction community. The barriers to the adoption of GBTs, such as higher cost and lack of awareness, further indicate that proper strategies need to be devised for promoting the wider adoption of GBTs in buildings development. However, there exist limited empirical studies identifying the strategies for promoting GBTs adoption in the construction industry. This study aims to identify the strategies that are important for promoting GBTs adoption in construction. After a comprehensive literature review to identify strategies for the promotion of GBTs adoption, empirical data were gleaned through a questionnaire survey with 104 green building experts around the world. The analysis results validated the importance of all of the 12 promotion strategies used for the study. Green building experts from different countries and with different backgrounds had significant agreement on the relative importance ranking of the promotion strategies. Furthermore, "financial and further market-based incentives for GBTs adopters", "availability of better information on cost and benefits of GBTs", "mandatory governmental policies and regulations", and "green rating and labeling" were identified as the top four important promotion strategies. The research findings provide a valuable reference to assist practitioners and policy makers in developing practical strategies for promoting GBTs adoption to eventually achieve the sustainable development of buildings. From the perspective of international experts, this study adds to the green building literature by offering empirical evidence of the important strategies for promoting GBTs adoption in the construction industry. Future research will investigate the interrelationships among the promotion strategies and their impacts on the GBTs adoption process.
\end{abstract}

Keywords: green building technologies; sustainability; sustainable development; promotion strategies; construction industry

\section{Introduction}

Greenhouse gas (GHG) emissions remain the primary factors driving global warming and climate change [1], and buildings play a central part in causing GHG emissions. According to Yudelson [2], globally, buildings are responsible for more than $40 \%$ of all GHG emissions. The United Nations Environment Programme (UNEP) [3] also reported that, globally, buildings account for up to $40 \%$ of total energy consumption and 30\% of GHG emissions. In specific countries such as Hong Kong, buildings account for nearly $70 \%$ of GHG emissions [4]. These facts show that the sustainable 
development of buildings would contribute significantly to the reduction in the amount of GHG emissions emanating from the construction industry into the atmosphere. Accordingly, in recent years, the need to improve the sustainability performance of buildings has become a major concern for the construction industry.

It is commonly acknowledged that green building is an effective approach through which the need for implementing sustainability and sustainable development within the construction industry can be addressed $[5,6]$. Green building was defined as "the practice of creating structures and using processes that are environmentally responsible and resource-efficient throughout a building's lifecycle" [7]. Thus, the development of green buildings would result in substantial minimization of negative environmental effects and efficient utilization of resources [8]. Hence, over the past two decades, there has been a growing focus on green buildings development, leading to an apparent shift towards green buildings throughout the world [9]. The popularity and acceptance gained by the green building practice have in turn caused the development of various green building technologies (GBTs) for enhancing the sustainability performance during the construction process. As defined by Ahmad et al. [10], GBTs are technologies that are incorporated into building design and construction to make the end product sustainable. There are many different GBTs applicable in the whole process of delivering building projects, with typical examples including solar system technology, green roof and wall technologies, and heat pump technology [11,12]. An integration of GBTs and interactions amongst other building systems and components are increasingly crucial to successfully implement green building and attain sustainability goals [13].

Adopting GBTs provides a wide variety of economic, social, and environmental benefits and, along with the growing awareness of climate change, these benefits play a huge role in pushing for the adoption and development of GBTs. Balaras et al. [14] indicated that the application of high energy efficient windows and green wall technology in housing development can help save $14-20 \%$ and $33-60 \%$ of operational energy, respectively. The estimation by Galante and Pasetti [15] showed that through retrofitting existing housing stock with high energy efficient wall technologies and materials, there is a great potential for the housing industry to save $24.8 \%$ of energy. Additionally, as Zhang et al. [12] observed, developer firms tend to adopt GBTs, such as solar technology and optimization of the thermal performance of building envelope, because that contributes to building up their competitive advantages, helping them gain good public image and reputation and get more market opportunities. In spite of the many benefits associated with GBTs, their implementation still encounters several kinds of barriers and problems. Previous studies discuss the various barriers affecting the adoption of GBTs in buildings development process, including higher costs of GBTs, a lack of interest and market demand, a lack of knowledge and awareness of GBTs and their benefits, a lack of government incentives, and resistance to change [11,12,16-18]. To effectively and efficiently promote the adoption of GBTs, it is necessary that proper strategies and policies be devised for overcoming the barriers in the industry.

However, the comprehensive literature review conducted as part of this study identified that there have been limited empirical studies identifying the strategies for promoting GBTs and practices adoption in the construction industry, which have so far also been only country-specific studies [8,19-21]. That is, regarding the strategies to promote the adoption of GBTs, the literature is dominated by suggestions of various scholars that lack empirical evidences to prove them. Moreover, the findings and implications of country-specific studies present some limitations when trying to apply them to GBTs adoption in the global construction industry. Given this background and in order to promote the adoption of GBTs in buildings development, this study aims to identify the strategies that are important for promoting GBTs adoption in the construction industry. Several issues influence GBTs adoption in the construction industry, and with the objective to investigate and gain a better understanding of these issues, an international questionnaire survey was performed. The survey was performed to collect and analyze the professional views of green building experts from different countries around the world to establish a common set of drivers for, barriers to, and strategies for promoting GBTs adoption. 
While the outcomes on the barriers and drivers are reported elsewhere [18,22], this paper reports upon the outcomes about the promotion strategies. The research findings not only add significantly to the existing green building body of knowledge, but also provide a valuable reference to assist practitioners and policy makers in developing practical strategies for promoting the adoption of GBTs to eventually achieve the sustainable development of buildings.

The remainder of the paper is organized into the following four sections. In Section 2, a review of some relevant studies relating to the strategies for promoting the adoption of GBTs and practices is presented. This is followed by Section 3, which describes the research methodology in detail. Section 4 presents and discusses the results of the statistical analyses. Section 5 presents the conclusions and implications of this study.

\section{Literature Review}

How to promote the widespread adoption of GBTs in the construction process has been a main concern for both industrial practitioners and scholars. Albeit the issue of adopting GBTs in the development of buildings is attracting worldwide attention, empirical research on the issue of strategies for promoting GBTs adoption in the construction industry is inadequate. There remain questions concerning the strategies that are applied to promote the successful adoption of GBTs in building projects. In this study, in pursing the research aim, a literature review was first conducted, through which the proposed promotion strategies for GBTs adoption were gathered.

There are various promotion strategies for GBTs and practices adoption that have been addressed in previous studies. For example, government's co-funding and incentives, policies and regulations for green development, and collaboration with research institutes and firms to study the benefits of green business parks have been identified as the most feasible solutions for overcoming the significant barriers to the adoption of green business parks, thus promoting green business parks adoption [8]. In addition, widening the coverage of government incentives to include the usage of green products and technologies, developing a project management framework for green construction, educating owners on the future benefits of green buildings, organizing construction tours to educate the public about the benefits of green building, and subsidy from government for research and development (R\&D) in green building systems and management have been identified strategies to promote the adoption of green building [19]. Furthermore, mandatory environmental regulations by the government, government and non-governmental organizations requirements (e.g., green label scheme), and establishment of standards (e.g., green specification) have been found as important factors in facilitating the successful adoption of green procurement in construction projects [20]. Financial and further market-based incentives, availability of better information on cost and benefits of GBTs, and green labeling and information dissemination have also been momentous in promoting GBTs adoption [21].

A framework on government measures for promoting building energy efficiency and green building was established by Qian and Chan [23], which comprises a wide range of measures including product rating and labeling, implementation of further market-based incentives, better enforcement of existing standards, subsidy from government, low-cost loans, and investment incentives. Potbhare et al. [24] pointed out that availability of better information on cost and benefits of green building guidelines, availability of institutional framework for effective implementation of green building guidelines, educational programs for developers, contractors, and policy makers related to green building guidelines, and creation of environmental awareness by workshops, seminars, and conferences were crucial strategies for promoting the rapid adoption of green building guidelines. To foster the adoption and development of green buildings, Li et al. [25] contended that it is critical to enhance the environmental awareness of stakeholders, strengthen technology research and communication, and formulate relevant policies and regulations. 
As a result of the emergence of green building, a number of green certificates, rating systems and labeling programs, e.g., Building Research Establishment Environmental Assessment Method (BREEAM) of UK, Leadership in Energy and Environmental Design (LEED) of US, Green Star of Australia, and Green Mark Scheme of Singapore, have been introduced to efficiently evaluate and measure green building development practices. There is consensus in the literature that these rating systems and labeling programs are instrumental in furthering the use of GBTs and practices [26-29]. Scholars have also argued that financial and regulatory incentive schemes are of great importance to the successful adoption of GBTs and practices [30-33]. Häkkinen and Belloni [34] further claimed that developing the awareness of clients about the benefits of green buildings is one of the most essential actions to encourage green building. Moreover, as the attitudes and behaviors of consumers and the public have a significant influence on the promotion of green building [35], strengthening publicity and education has been considered an effective means to boost public awareness of environmental sustainability and customers' willingness to pay for green buildings [28]. After a careful review of the literature, Table 1 provides a list of 12 proposed strategies for promoting GBTs adoption in the construction industry. 
Table 1. List of identified promotion strategies for GBTs adoption.

\begin{tabular}{|c|c|c|c|c|c|c|c|c|c|c|c|c|c|c|c|c|c|c|c|c|c|c|c|c|}
\hline \multirow{2}{*}{ Code } & \multirow{2}{*}{ Promotion Strategies } & \multicolumn{23}{|c|}{ References } \\
\hline & & [8] & [19] & [21] & [36] & {$[20]$} & {$[37]$} & {$[23]$} & {$[30]$} & {$[38]$} & {$[27]$} & [39] & [40] & {$[28]$} & [31] & [32] & {$[24]$} & [41] & {$[42]$} & [43] & [25] & [29] & {$[44]$} & [45] \\
\hline P01 & $\begin{array}{l}\text { Financial and further market-based incentives } \\
\text { for GBTs adopters }\end{array}$ & $\sqrt{ }$ & $\sqrt{ }$ & $\sqrt{ }$ & $\sqrt{ }$ & & & $\sqrt{ }$ & $\sqrt{ }$ & & & & $\sqrt{ }$ & $\sqrt{ }$ & $\sqrt{ }$ & $\sqrt{ }$ & $\sqrt{ }$ & $\sqrt{ }$ & $\sqrt{ }$ & & $\sqrt{ }$ & & & \\
\hline P02 & $\begin{array}{c}\text { Mandatory governmental policies and } \\
\text { regulations }\end{array}$ & $\sqrt{ }$ & & $\sqrt{ }$ & $\sqrt{ }$ & $\sqrt{ }$ & $\sqrt{ }$ & $\sqrt{ }$ & $\sqrt{ }$ & $\sqrt{ }$ & & & $\sqrt{ }$ & $\sqrt{ }$ & & & $\sqrt{ }$ & $\sqrt{ }$ & $\sqrt{ }$ & $\sqrt{ }$ & $\sqrt{ }$ & & $\sqrt{ }$ & \\
\hline $\mathrm{P} 03$ & Green rating and labeling & & & $\sqrt{ }$ & $\sqrt{ }$ & $\sqrt{ }$ & & $\sqrt{ }$ & & & $\sqrt{ }$ & $\sqrt{ }$ & $\sqrt{ }$ & $\sqrt{ }$ & & & & $\sqrt{ }$ & & & $\sqrt{ }$ & $\sqrt{ }$ & & \\
\hline P04 & $\begin{array}{l}\text { Better enforcement of existing green building } \\
\text { policies and standards }\end{array}$ & & & & & & & $\sqrt{ }$ & & & & & & & & & & & & & $\sqrt{ }$ & & $\sqrt{ }$ & $\sqrt{ }$ \\
\hline P05 & Low-cost loans and subsidy from government & & $\sqrt{ }$ & & & & & $\sqrt{ }$ & & & & & & $\sqrt{ }$ & & & $\sqrt{ }$ & & & & $\sqrt{ }$ & & & $\sqrt{ }$ \\
\hline P06 & $\begin{array}{c}\text { Public environmental awareness creation } \\
\text { through workshops, seminars, } \\
\text { and conferences }\end{array}$ & & & $\sqrt{ }$ & & & & & $\sqrt{ }$ & & & & & $\sqrt{ }$ & & & $\sqrt{ }$ & $\sqrt{ }$ & & & $\sqrt{ }$ & & $\sqrt{ }$ & \\
\hline P07 & $\begin{array}{l}\text { More publicity through media (e.g., print } \\
\text { media, internet, and radio and television } \\
\text { programs) }\end{array}$ & & & $\sqrt{ }$ & & & & & & & & & & $\sqrt{ }$ & & & $\sqrt{ }$ & & & & & & & \\
\hline P08 & $\begin{array}{l}\text { Educational programs for developers, } \\
\text { contractors, and policy makers related to GBTs }\end{array}$ & $\sqrt{ }$ & & $\sqrt{ }$ & & & & & $\sqrt{ }$ & & & & & $\sqrt{ }$ & & & $\sqrt{ }$ & & & & & & $\sqrt{ }$ & \\
\hline P09 & $\begin{array}{l}\text { Availability of better information on cost and } \\
\text { benefits of GBTs }\end{array}$ & $\sqrt{ }$ & $\sqrt{ }$ & $\sqrt{ }$ & & $\sqrt{ }$ & & & $\sqrt{ }$ & $\sqrt{ }$ & & & & & & & $\sqrt{ }$ & & & & $\sqrt{ }$ & & & \\
\hline P10 & $\begin{array}{l}\text { Competent and proactive GBTs promotion } \\
\text { teams/local authorities }\end{array}$ & & & $\sqrt{ }$ & & & & & $\sqrt{ }$ & & & & & & & & $\sqrt{ }$ & & & & & & & \\
\hline P11 & $\begin{array}{l}\text { Availability of institutional framework for } \\
\text { effective implementation of GBTs }\end{array}$ & $\sqrt{ }$ & $\sqrt{ }$ & $\sqrt{ }$ & & & & & & & & & & & & & $\sqrt{ }$ & & & & & & & \\
\hline $\mathrm{P} 12$ & $\begin{array}{l}\text { A strengthened GBTs research and } \\
\text { communication }\end{array}$ & $\sqrt{ }$ & $\sqrt{ }$ & $\sqrt{ }$ & & & & & & & & & & $\sqrt{ }$ & & & & & & & $\sqrt{ }$ & & & \\
\hline
\end{tabular}

References: Hwang et al. (2017) [8]; Hwang and Tan (2012) [19]; Darko et al. (2017) [21]; Darko et al. (2017) [36]; Wong et al. (2016) [20]; Yang and Zhang (2012) [37]; Qian and Chan (2007) [23]; Chan et al. (2009) [30]; Lam et al. (2009) [38]; Windapo (2014) [27]; Li et al. (2017) [39]; Shi et al. (2013) [40]; Zhang (2015) [28]; Olubunmi et al. (2016) [31]; Qian et al. (2016) [32]; Potbhare et al. (2009) [24]; Gou et al. (2013) [41]; Mulligan et al. (2014) [42]; Shen et al. (2016) [43]; Li et al. (2014) [25]; Murtagh et al. (2016) [29]; Gan et al. (2015) [44]; Van Doren et al. (2016) [45]. 


\section{Research Methodology}

\subsection{Questionnaire Design}

According to Tan [46], the questionnaire survey is a methodical technique of gathering data based on a sample. The questionnaire survey method has been extensively used to solicit professional opinions in green building research $[47,48]$. In this study, an empirical questionnaire survey was performed to investigate the relative importance of the proposed strategies in promoting GBTs adoption in the construction industry. Carrying out a questionnaire survey is advantageous for achieving "quantifiability and objectiveness" [49]. The comprehensive literature review laid the basis for the development of the survey questionnaire. The main questionnaire comprised three parts. The research objectives and contact details were presented in Part I. Part II was designed to glean background information of the experts, e.g., position, years of experience, and profession. Then, in Part III, a list of 26 barriers to the adoption of GBTs, a list of 21 drivers for the adoption of GBTs, and a list of 12 promotion strategies for the adoption of GBTs were presented. First, the experts were asked to assess the criticalities of the barriers to the adoption of GBTs using a five-point Likert scale ranging from 1 (not critical) to 5 (very critical). In addition, the experts were asked to indicate their professional opinions on the main drivers for adopting GBTs using a five-point Likert scale ranging from 1 (strongly disagree) to 5 (strongly agree). Finally, the experts were asked to assess the importance of each strategy in promoting the adoption of GBTs using a five-point Likert scale ranging from 1 (not important) to 5 (very important). For each of the five-point Likert scales, the middle value was 3 (being neutral). Note that only the question on the promotion strategies for the adoption of GBTs is of interest to the present paper, and a sample of the relevant section of the questionnaire is provided in Appendix A in order to get a better understanding of the survey. This study adopted the five-point Likert scale, because it gives results that are not only unambiguous, but are also easy to interpret [50]. Moreover, the use of five-point Likert scale has been popular in the green building domain [12,51]. A pilot study was conducted to test the comprehensibility and suitability of the questionnaire prior to the survey. The pilot study involved a team of three professors, a senior lecturer, and a postgraduate researcher who were experienced in this research area. Most of them, especially the professors, had both industry and research/academic experience in green building. The questionnaire was finalized based on feedback from the pilot study.

\subsection{Data Collection and Analysis}

Through email, the questionnaire was distributed to carefully selected international green building experts (both practitioners and academics), who were primarily identified through research publications and databases (member directories) of worldwide Green Building Councils. This study adopts Cabaniss's [52] (p. 42) definition of an expert: “an expert is someone with special skills or knowledge evidenced by his/her leadership in professional organizations, holding office in professional organizations, presenter at national conventions, published in recognized journals, etc." Therefore, in this study, the suitability of the initially identified experts was determined based on their knowledge and understanding of GBTs and practices adoption in the construction industry, evidenced by their relevant green building research publications (to respect the anonymity of the experts, examples of the publications are not provided) and/or registration as accredited green professionals with recognized green building councils (such as the World Green Building Council, United States Green Building Council (USGBC), United Kingdom Green Building Council, Green Building Council Australia, and Canada Green Building Council). That is, the purposive sampling technique was adopted for data collection. The purposive sampling is a non-probability sampling method that is most effective for selecting knowledgeable experts based on the purpose of the study, hence the name [53]. Bias exists in all research regardless of the methodology used and it is difficult to eliminate [54,55]. However, it is crucial for researchers to attempt to minimize bias; thus, in this study, measures were implemented to reduce bias. For example, the adoption of purposive sampling 
helped in reducing bias. Purposive sampling has proved to have advantages over other sampling methods, such as convenience sampling, in that it reduces bias as the sample is constantly refined to meet the study aims [55]. Pretesting the survey questionnaire by the pilot study described earlier was also an essential step toward developing a robust research and thereby minimizing design bias. Another measure that was employed to minimize non-response bias in this research was maximizing follow-up during the data collection phase using reminder emails $[55,56]$.

All questionnaires were emailed to the experts, attaching a Microsoft Word file and a web link produced by survey monkey to allow online responses. Because of resource constraints, it was difficult to produce different language versions of the questionnaire, so only an English version of the questionnaire was used for the survey based on the assumption that most of the selected experts could write, read, and understand English. In order to encourage participation, it was communicated to the experts, in the survey questionnaire, that the research outcomes can be shared with them [57]. Besides, to increase the sample size, the experts were requested to forward the questionnaire to their colleagues, industry friends, and other professionals they knew also have rich experience in or knowledge of GBTs adoption in the construction industry. Due to this approach to sample data collection (similar to Cheng and Li [58] and Rahman [59]), the exact number of distribution is unknown and hence the response rate cannot be calculated, however, more than 500 questionnaires were sent out. The questionnaire survey was conducted over a three-month period (early March to early June 2016), and at the end of the period, 104 valid responses regarding GBTs adoption were received from green building experts from 20 different countries (including the United States, Canada, Australia, United Kingdom, China, Hong Kong, Malaysia, Singapore, Mexico, Brazil, India, Egypt, etc.). Considering the difficulties in eliciting international responses [58], 104 responses from qualified experts could be deemed representative and reasonable. Additionally, numerous scholars agree and suggest that a minimum sample size of 30 is representative of any group [60,61]. Owing to the word/space limitation, all of the countries and the number of responses received from each country, as well as background information of the green building experts are fully reported elsewhere [18].

Analysis of the experts' background information signified that the reliability and credibility of the findings from this study are high, for the reason that most of the experts held top positions in their organizations, e.g., senior manager $(26 \%)$, director/CEO $(21 \%)$, and professor $(19 \%)$. Moreover, all of the experts had been involved in activities related to the adoption of GBTs before, such as actual green building projects implementation and participation in various types of meetings (e.g., business conferences and government meetings) in support of GBTs adoption, with more than half (59\%) of them having hands-on experience in green building projects. Furthermore, the major proportion of the experts $(71 \%)$ had more than 5 years of experience in green building.

The collected data were analyzed using the SPSS 20.0 statistical package. This study performed the data analyses by employing various statistical analysis methods in a six-level data analyses framework (Figure 1), which was modified from the five-level data analyses framework used by Choi [62] as well as the six-level data analyses framework used by Wong et al. [20]. Thus, the data analyses framework for the present study comprises six different statistical analysis techniques: (1) Cronbach's alpha coefficient test; (2) the mean value/score ranking technique; (3) one sample $t$-test; (4) Kendall's coefficient of concordance test (Kendall's W); (5) analysis of variance (ANOVA) test; and (6) the mean difference analysis (Figure 1). First, Cronbach's alpha coefficient test was used to assess the reliability of the data for further analyses. Cronbach's alpha coefficient assesses reliability through examination of the internal consistency under the adopted scale of measurement [63]. Second, the mean value ranking technique was used to determine the relative importance and rankings of the proposed promotion strategies for GBTs adoption. In construction management research, the mean value ranking technique has been widely used and considered an effective method to easily identify key factors among several individual factors $[64,65]$. Third, the one sample $t$-test was adopted to test the significance of the mean values of the importance of the promotion strategies [21,61]. In addition, Kendall's $W$ was calculated to test the overall agreement among different green building experts' rankings of the promotion strategies 
within a certain group $[40,66]$. Kendall's $W$ was adopted in this study because it does not assume any specific nature of data distribution [67]. The ANOVA test was also employed to check for statistically significant differences in the importance mean values of the promotion strategies across different expert groups $[18,59]$. The ANOVA test was chosen over other tests, such as the Mann-Whitney $\mathrm{U}$ Test, since it is a suitable method for comparing the mean values of more than two groups [68]. Lastly, the mean difference analysis was done to determine the actual values of the differences in the importance mean values of the promotion strategies from two different groups [8,51].

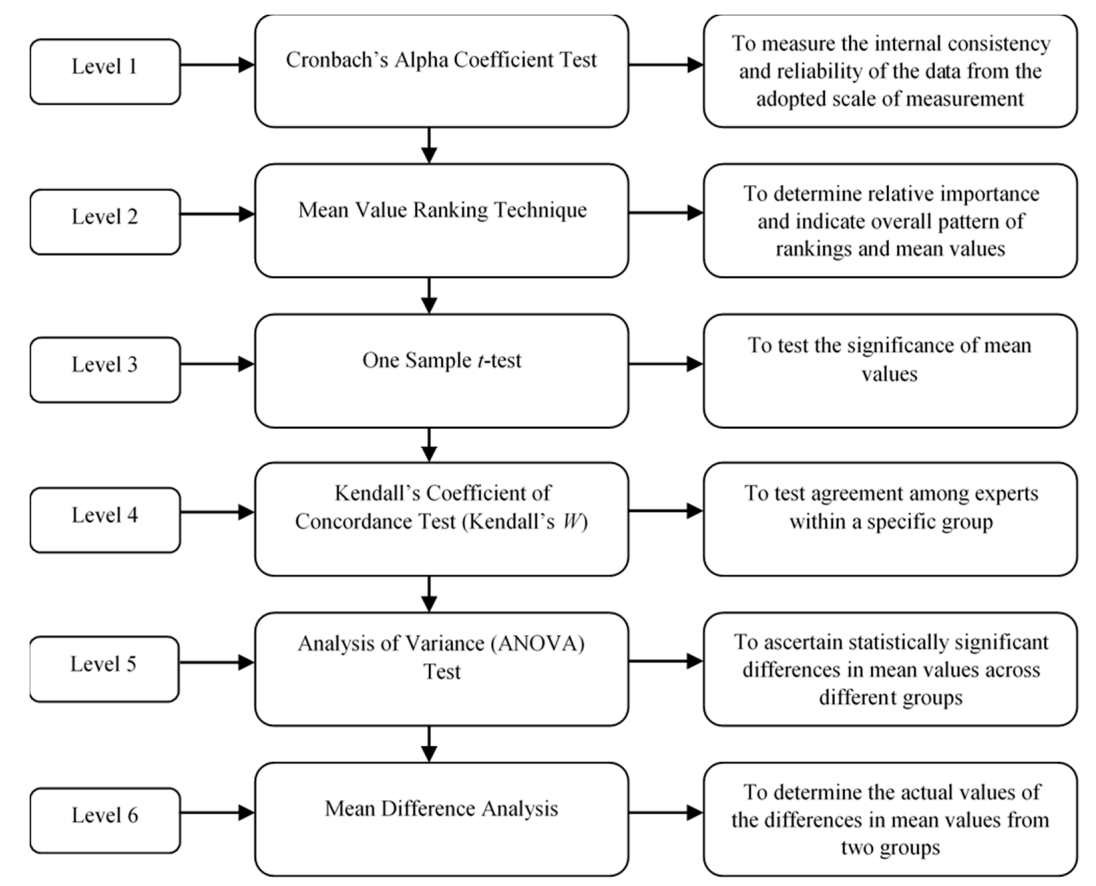

Figure 1. Six-level data analyses framework.

\section{Analysis Results and Discussion}

Because the relative importance of the various promotion strategies was evaluated by using the five-point Likert scale, Cronbach's alpha coefficient was used to measure the internal consistency of the data to assess the reliability of the five-point Likert scale. Cronbach's alpha coefficient ranges from 0 to 1 , where 1 indicates the highest level of validity and reliability of the quantitative inputs [63]. The Cronbach's alpha coefficient of the promotion strategies was 0.823 , which is above the threshold of 0.7 [69], representing high data reliability.

After checking the reliability of the data, this study analyzed the importance of the promotion strategies by using methods that include the descriptive mean values and one sample $t$-test. At a $95 \%$ level of confidence with a $0.05 p$-value, and against a test value of 3.00 which is the average of the rating scale, the one sample $t$-test was used to test the mean values of the importance of the promotion strategies. The null hypothesis, $H_{0}$, is that "the mean value is not statistically significant", whereas the alternative hypothesis, $H_{1}$, is that "the mean value is statistically significant". The null hypothesis ought to be rejected if a $p$-value is less than 0.05 . The summary of the survey results on the relative importance of the promotion strategies is shown in Table 2. The mean values of the importance of the promotion strategies can also be presented graphically, as shown in Figure 2. As can be seen from the results, the importance mean values of the promotion strategies are all statistically greater than the test value of 3.00. Moreover, all of the $p$-values obtained from the one sample $t$-test are less than 0.05 (Table 2). These results indicate that all of the 12 promotion strategies were considered to be significantly important, implying that these strategies had an enabling role in promoting GBTs adoption in the construction industry. 
Table 2. Summary of the survey results on the importance of the promotion strategies for GBTs adoption.

\begin{tabular}{|c|c|c|c|c|c|c|c|c|c|c|c|c|c|c|}
\hline \multirow{2}{*}{ Code } & \multicolumn{4}{|c|}{ All Experts } & \multicolumn{2}{|c|}{ US } & \multicolumn{2}{|c|}{ CA } & \multicolumn{2}{|c|}{ AU } & \multicolumn{3}{|c|}{ Diff. } & \multirow{2}{*}{ ANOVA } \\
\hline & Mean & Rank & $p$-Value & ANOVA & M(US) & Rank & M(CA) & Rank & $\mathrm{M}(\mathrm{AU})$ & Rank & Diff. (US-CA) & Diff. (US-AU) & Diff. (CA-AU) & \\
\hline P01 & 4.33 & 1 & $0.00^{\mathrm{a}}$ & $0.71^{\mathrm{b}}$ & 4.30 & 1 & 4.27 & 1 & 4.18 & 2 & 0.03 & 0.12 & 0.09 & $0.87^{b}$ \\
\hline P02 & 4.15 & 3 & $0.00^{\mathrm{a}}$ & $0.33^{b}$ & 3.97 & 4 & 4.07 & 4 & 4.36 & 1 & -0.10 & -0.39 & -0.29 & $0.42^{b}$ \\
\hline P03 & 4.02 & 4 & $0.00^{a}$ & $0.45^{b}$ & 4.00 & 3 & 3.80 & $6^{c}$ & 4.00 & $4^{c}$ & 0.20 & 0.00 & 0.20 & $0.74^{b}$ \\
\hline P04 & 3.77 & 8 & $0.00^{\mathrm{a}}$ & $0.22^{b}$ & 3.52 & $10^{c}$ & 3.80 & $6^{c}$ & 3.73 & $9^{c}$ & -0.28 & -0.21 & 0.07 & $0.55^{b}$ \\
\hline P05 & 3.81 & 7 & $0.00^{\mathrm{a}}$ & $0.31^{b}$ & 3.73 & 7 & 3.80 & $6^{c}$ & 3.82 & $6^{c}$ & -0.07 & -0.09 & -0.02 & $0.95^{b}$ \\
\hline P06 & 3.68 & 11 & $0.00^{\mathrm{a}}$ & $0.11^{b}$ & 3.36 & 12 & 3.60 & $10^{c}$ & 3.64 & $11^{\mathrm{c}}$ & -0.24 & -0.28 & -0.04 & $0.60^{b}$ \\
\hline P07 & 3.65 & 12 & $0.00^{\mathrm{a}}$ & $0.29^{b}$ & 3.61 & $8^{c}$ & 3.60 & $10^{c}$ & 3.73 & $9^{c}$ & 0.01 & -0.12 & -0.13 & $0.91^{b}$ \\
\hline P08 & 3.91 & 6 & $0.00^{\mathrm{a}}$ & $0.13^{b}$ & 3.88 & $5^{c}$ & 3.93 & 5 & 3.64 & $11^{\mathrm{c}}$ & -0.05 & 0.24 & 0.29 & $0.55^{b}$ \\
\hline P09 & 4.20 & 2 & $0.00^{\mathrm{a}}$ & $0.57^{b}$ & 4.21 & 2 & 4.20 & 2 & 4.09 & 3 & 0.01 & 0.12 & 0.11 & $0.91^{b}$ \\
\hline P10 & 3.72 & 10 & $0.00^{\mathrm{a}}$ & $0.46^{b}$ & 3.61 & $8^{c}$ & 3.60 & $10^{c}$ & 3.82 & $6^{c}$ & 0.01 & 0.21 & -0.22 & $0.66^{b}$ \\
\hline P11 & 3.75 & 9 & $0.00^{\mathrm{a}}$ & $0.37^{b}$ & 3.52 & $10^{c}$ & 3.67 & 9 & 3.82 & $6^{c}$ & -0.15 & -0.30 & -0.15 & $0.54^{b}$ \\
\hline P12 & 3.96 & 5 & $0.00^{\mathrm{a}}$ & $0.20^{b}$ & 3.88 & $5^{c}$ & 4.13 & 3 & 4.00 & $4^{c}$ & -0.25 & -0.12 & 0.13 & $0.41^{b}$ \\
\hline
\end{tabular}

Note: US = United States; CA = Canada; $\mathrm{AU}=$ Australia; $\mathrm{M}(\mathrm{US})=$ mean value from United States; $\mathrm{M}(\mathrm{CA})=$ mean value from Canada; $\mathrm{M}(\mathrm{AU})=$ mean value from Australia; Diff. $=$ difference
in means; Diff. (US-CA) = difference in means from United States and Canada; Diff. (US-AU) = difference in means from United States and Australia; Diff. (CA-AU) = difference in means from Canada and Australia; ${ }^{a}$ The one sample $t$-test result is significant at the 0.05 significance level $(p$-value $<0.05)\left(2\right.$-tailed); ${ }^{b}$ The ANOVA result is insignificant at the 0.05 significance level (sig. > 0.05); ${ }^{\mathrm{C}}$ Equal rank, wherein the next rank is skipped. 


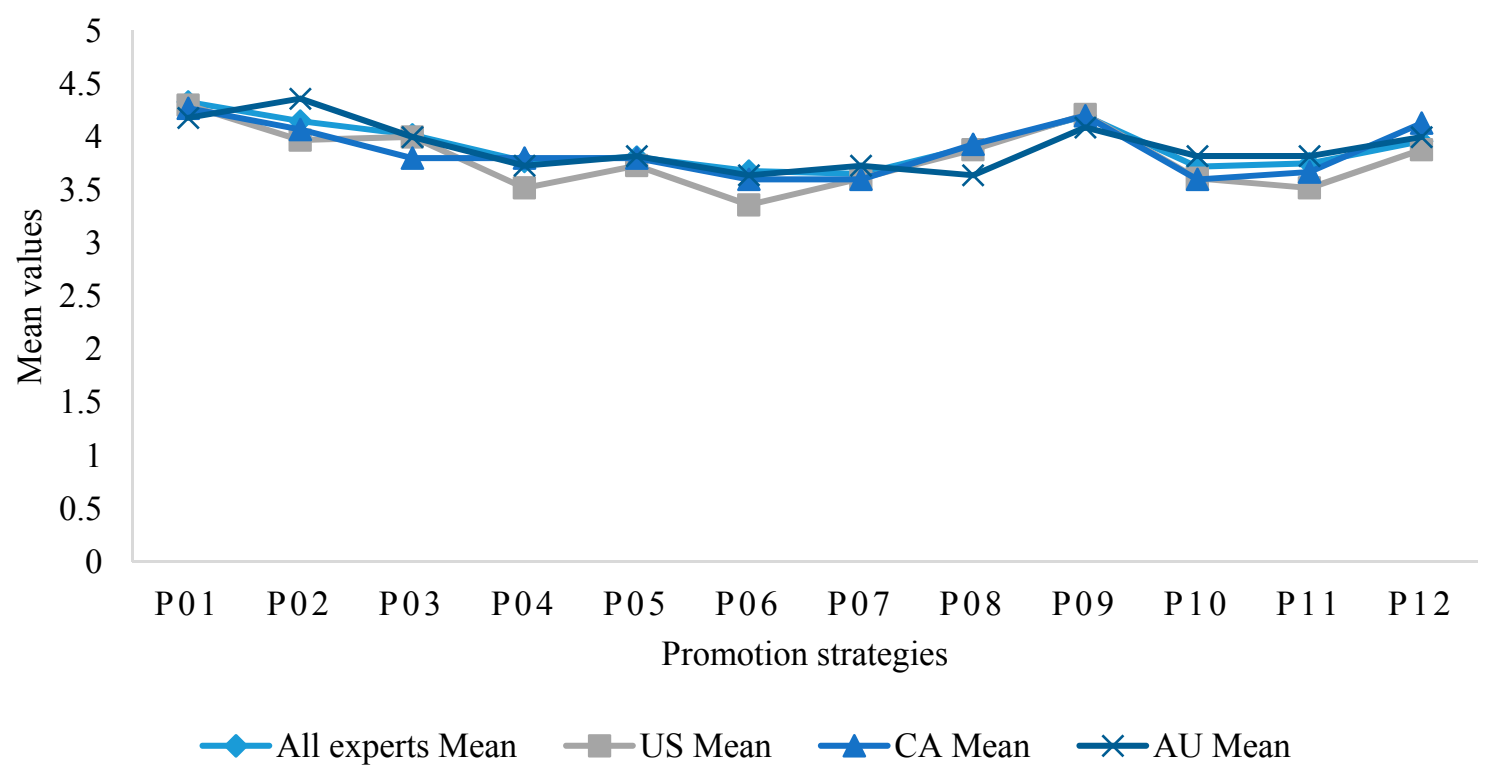

Figure 2. Line graph of the mean values of the promotion strategies.

Since the experts were from different countries and thus had different backgrounds and experiences, it was essential to check whether they agreed on the ranking of the importance of the promotion strategies, which was done by using Kendall's W, as said earlier. The value of Kendall's $W$ ranges from 0 to 1 , where a value of 0 indicates "no agreement" within the group on the ranking of a set of factors, and 1 indicates "complete agreement" [66]. In this study, the value of Kendall's $W$ for ranking the 12 promotion strategies by all of the experts was 0.104 , which was statistically significant at the 0.000 level. However, as suggested by the literature [66], in view of the fact that the promotion strategies were more than seven and the sample size was also larger than 20 (i.e., 104 experts), the Chi-Square value, rather than the Kendall's $W$ value, should be used. Under the degree of freedom (df) of 11, the calculated Chi-Square value was 118.819 with a probability of occurrence under $p<0.001$ (asymptotic significance (Asymp. Sig.) $=0.000$ ). This indicates that, despite the dissimilar backgrounds and experiences of the experts, they had a significant degree of agreement regarding the ranking of the promotion strategies for GBTs adoption. Furthermore, from the ANOVA results, it can be inferred that the experts agreed on the relative importance of all of the promotion strategies, because the ANOVA (Sig.) value of each promotion strategy was above 0.05 (Table 2). Thus, the mean values of the importance of each promotion strategy across different expert groups did not significantly differ, suggesting that the professional views of the experts from different countries are quite consistent on the issue under study. Therefore, the results should aid both developed and developing countries in understanding the important strategies to put in place for nurturing the adoption of GBTs. Another issue that may exist in this worldwide sample is geographical and cultural differences, which might affect the responses provided by the experts. Nevertheless, many researchers have emphasized that geographical and cultural differences are arduous to handle and manage in a research study, and to reduce the complexity of the research, geographical and cultural differences are usually understated or simply ignored [70,71]. The use of well-known factors in the literature contributes to reducing the effects of geographical and cultural issues in this study [58]. In addition, from the results of mean, the top six important promotion strategies (mean $\geq 3.91$ ) perceived by the experts in descending order are "financial and further market-based incentives for GBTs adopters" (P01), "availability of better information on cost and benefits of GBTs" (P09), "mandatory governmental policies and regulations" (P02), "green rating and labeling" (P03), "a strengthened GBTs research and communication" (P12), and "educational programs for developers, contractors, and policy makers related to GBTs" (P08). These six promotion strategies are discussed below. 
"Financial and further market-based incentives for GBTs adopters" (P01) was ranked first with a very high mean value of 4.33 , indicating that incentives from the government and other private parties, such as financial institutions, interested in green building developments have had the highest level of influence in driving construction stakeholders to embrace GBTs. Incentive policies are considered as the most important strategy for the advancement of GBTs adoption. This finding confirms the viewpoints of various researchers [30-32] that incentive schemes are very crucial for the promotion of green building developments. Financial incentives provide a valuable economic support for the industry, particularly individual stakeholders or firms, in the adoption process of GBTs which usually involves higher investment than adopting traditional building technologies. Therefore, as economic issues remain the most essential issues for the business survival of every stakeholder [30], it holds true that providing financial and further market-based incentives to market stakeholders can greatly encourage them to adopt GBTs. Moreover, Maxwell et al. [72] maintained that unless green building developments have a sufficient market demand, financial incentives, such as tax incentives and direct grants, are necessary conditions to help share the additional costs in GBTs. In the U.S., for example, tax incentives, where GBTs adopters are offered tax deductions or are totally exempted from paying tax, have been the most popular incentive provided by the government to promote GBTs adoption [73]. Non-financial or further market-based incentives, such as expedited permitting and density bonus or gross floor area incentive scheme, have also been very effective in motivating the adoption of GBTs in Hong Kong [41].

"Availability of better information on cost and benefits of GBTs" (P09) (mean $=4.20$ ) occupied the second position, implying that making relevant information available is another effective means of promoting GBTs adoption. Due to the high initial investment, stakeholders who have adequate, accurate, and better information about and knowledge of the attendant lifecycle benefits of adopting GBTs are most likely to adopt GBTs. This finding is consistent with the study done by Potbhare et al. [24] where the availability of better information on cost and benefits of green building guidelines was identified as one of the top two strategies for catalyzing the adoption of green building guidelines in India. This promotion strategy is highly associated with the conduct of GBTs research and information sharing, which could be an explanation for why "a strengthened GBTs research and communication" (P12) (mean $=3.96)$ was ranked fifth. The findings of this study provide concrete evidence that conducting robust and credible studies that are devoted to GBTs to clearly and accurately show, verify, and quantify the real cost and benefits resulting from the adoption of GBTs is very important for attracting the interest of stakeholders, such as investors and developers. This research finding has been widely supported by the literature $[8,19,25,74,75]$. To successfully conduct such researches, it is essential that the government and other professional funding agencies boost research funding allocated to green buildings. The establishment of some supporting structures like GBTs research centers or institutes is also a welcome means for helping and strengthening GBTs-related research to further promote GBTs adoption. Additionally, the communication and dissemination of information and research findings concerning innovative green technologies available in the market and their cost/benefits data is considered a helpful way of successfully increasing the pace of adoption of GBTs. Establishing a comprehensive national database of GBTs or having a dedicated website is valuable for facilitating a better platform to share the GBTs-related information and research findings for promoting the adoption of GBTs [21,38].

"Mandatory governmental policies and regulations" (P02) (mean = 4.15) was ranked third, indicating that government policies and regulations are key drivers in GBTs adoption and implementation. Whether it is due to the perceived high initial capital costs, or it is due to other hindrances, such as the lack of interest and market demand, the adoption of GBTs in the construction industry is the kind of activity in which "if you don't legislate, people won't start to do it" [41] (p. 170). Hence, the importance of imposing mandatory policies and regulations for green building development on the market stakeholders is high in promoting and encouraging the adoption of GBTs. Wong et al. [20] also found that the mandatory environmental regulations by the government were the most important 
factor for the success of implementing green procurement in Hong Kong. In addition, in China, policy pressure was identified as the main reason why developers adopt green procurement [43]. Formulating mandatory policies and regulations for GBTs adoption is important for stimulating market interest in GBTs, because that motivates, forces, or exerts pressure on the industry practitioners to take relevant actions for GBTs adoption in order to avoid fines or penalties for implementing traditional technologies. This promotion strategy is closely related to the provision of incentives in that normally stakeholders are required to fulfill some mandatory or compulsory requirements before benefiting from the incentive schemes.

"Green rating and labeling" (P03) (mean $=4.02)$ received the fourth position, indicating that green building rating systems play a critical role in promoting the adoption of GBTs. Rating and labeling a building as a green building gives it and the owner an interesting recognition within the industry, and the desire to obtain such a recognition pushes stakeholders to take part in GBTs adoption. According to Ali and Al Nsairat [76], a green building rating system is a tool for assessing whether a building is "green", and after detailed assessment, the building is given a green label and rank. Green building rating systems are important to GBTs adoption promotion because they provide useful and helpful guidance and information concerning green building to the industry professionals and the public [77]. Furthermore, green building rating systems are helpful in producing more accredited and skilled green professionals to assist the adoption of GBTs in the industry. For example, Singapore has launched green building rating systems and labeling programs that help to nurture a lot of green professionals such as Green Mark Professionals (GMPs), Green Mark Managers (GMMs), and Green Mark Facilities Managers (GMFM) [78]. Although internationally recognized green building rating systems, such as BREEAM and LEED, are supportive for promoting the adoption of GBTs at both the national and international levels, it is worth nothing that green building varies among countries owing to the different local climatic conditions [79], thus it may be required to develop authoritative green building rating systems and labeling programs to suit specific local environments/climates to promote the wider adoption of GBTs in a more efficient manner in specific countries/locations. In addition, in developing the green building rating systems, careful attention needs to be paid to maximizing their robustness and effectiveness as that has a pivotal role to play in the successful adoption and promotion of GBTs [39].

"Educational programs for developers, contractors, and policy makers related to GBTs" (P08) $($ mean $=3.91)$ was ranked sixth. Lack of knowledge and awareness of GBTs has become a barrier to GBTs adoption [18], and this barrier could be overcome by providing related education to raise the knowledge and awareness levels of the industry practitioners. As developers, contractors, and policy makers are major players in the adoption of GBTs, it is considered that organizing educational programs to increase knowledge and awareness among them is essential to drive the adoption of GBTs. A similar situation was also identified by Potbhare et al. [24] where educational programs for developers, contractors, and policy makers related to green building guidelines was an important strategy for promoting green building guidelines adoption. Chan et al. [30] also pointed out that education and awareness champions are always the welcome means for continuous promotion of a green building market, and the task could be shared between industry associations and governmental and non-governmental organizations. While providing GBTs education to these three groups of stakeholders is valuable for encouraging the adoption of GBTs in the industry, to further foster GBTs adoption, educating the entire public should also be an important approach to enhance the attractiveness of GBTs in society. Society's attitude toward GBTs could be translated into market demand, which impacts corporate behavior, and this can originate from public education [77].

As a supplement to the overall perception from the green building experts from 20 different countries around the globe, as shown in Table 2, this study also briefly analyzed the differences in the perception between the experts from three selected countries: United States, Canada, and Australia. These three countries were selected for this analysis because they were the countries where the majority of the responses were received from: 33 responses from the United States, 15 from Canada, and 11 from 
Australia (see Chan et al. [18]). Generally, the perception of the importance of the promotion strategies from the Australian experts was higher than that from the United States and Canadian experts, which may imply that the identified promotion strategies have encouraged the Australia experts more to adopt GBTs. Moreover, the United States experts and the Canadian experts had the largest difference in the perception of the importance of "Better enforcement of existing green building policies and standards" (P04, Diff. (US-CA) $=0.28$ ). For the United States experts and the Australian experts, they had the largest difference in the perception of the importance of "Mandatory governmental policies and regulations" (P02, Diff. (US-AU) $=0.39$ ). The Canadian experts and Australian experts had the largest difference in the perception of the importance of two promotion strategies: "Mandatory governmental policies and regulations" (P02, Diff. $(\mathrm{CA}-\mathrm{AU})=0.29)$ and "Educational programs for developers, contractors, and policy makers related to GBTs" (P08, Diff. (CA-AU) $=0.29)$. Nonetheless, all of these mean differences are not statistically large as they were all less than 0.50 . This was further confirmed by the ANOVA results where no statistically significant differences were found in the mean values of the importance of the promotion strategies across the three expert groups (Table 2). The results suggest that, generally, the identified strategies are important for any country in promoting the adoption of GBTs.

\section{Conclusions and Implications}

Green building technologies (GBTs) are gaining an increasing interest in the construction industry globally because adopting GBTs is a way of enhancing the sustainability performance of buildings. To promote the widespread adoption of GBTs in buildings development, this study identified the strategies that are important for promoting GBTs adoption in the construction industry. Twelve promotion strategies were identified through a comprehensive review of the literature and presented in a questionnaire. Then, a questionnaire survey was conducted with 104 international green building experts to evaluate the relative importance of these promotion strategies. The results of this study first indicated that all of the 12 promotion strategies were significantly important in promoting GBTs adoption in the construction industry. In addition, "financial and further market-based incentives for GBTs adopters", "availability of better information on cost and benefits of GBTs", "mandatory governmental policies and regulations", and "green rating and labeling" were the top four strategies greatly promoting the adoption of GBTs. Furthermore, there was a significant degree of agreement among the green building experts regarding the relative importance ranking of the promotion strategies, and the differences in importance of the promotion strategies between different expert groups were not statistically large/significant. Given the limited empirical studies on the promotion strategies for GBTs adoption, the empirical results of this study make a significant contribution to the green building body of knowledge. Moreover, the findings of this study can serve as a valuable reference for assisting practitioners and policy makers in the development of practical strategies for promoting GBTs adoption to eventually achieve the sustainable development of buildings.

The necessary empirical data for the research reported in this paper were collected from international green building experts, rather than experts in a particular country, and hence have a global outlook. Consequently, the findings and implications of this study can be helpful and useful for policy makers and practitioners in developed as well as developing countries. This study has presented 12 important strategies for the promotion of GBTs adoption. The implication is that, in those countries where the green building practice is still at the preliminary stage and therefore policy makers and other relevant professional bodies and advocates have yet to develop strategies to facilitate the adoption of GBTs, they can first focus and act based upon the promotion strategies with high relative importance or mean values. On the other hand, in countries where the green building industries are better developed and matured and therefore all or some of the identified strategies are already in place for encouraging GBTs adoption, the policy makers should regularly monitor the performance of the existing strategies to maximize their robustness and effectiveness for the continuous promotion of GBTs adoption. 
This study has some limitations that warrant future research attention. Considering the large number of barriers and drivers of GBTs adoption assessed by the international experts in the survey questionnaire and the likely busy schedules of work for the experts, it was reasonable to keep the list of promotion strategies as short and simple as possible, in order to guarantee the quality and reliability of their responses. Nevertheless, this study still builds a foundation for launching further empirical international and country-specific studies on the strategies for promoting GBTs adoption in the construction market. A natural extension of this study would be to increase the number of promotion strategies examined in this study. Moreover, the importance evaluation made in this study could be influenced by the different backgrounds, attitudes, and experiences of the experts, caused by their geographical and cultural differences, because it was subjective. However, it was outside the scope of this study to investigate the differences in the opinions from the various experts based upon geographical and cultural differences and how these differences affect their opinions. Future research could also investigate and model the interrelationships among the promotion strategies and their impacts on the GBTs adoption process.

Acknowledgments: This study forms part of a larger-scope Ph.D. study on the promotion of GBTs adoption where related papers, but with different scopes and objectives have been published. The authors are thankful to the Department of Building and Real Estate of The Hong Kong Polytechnic University for funding this research. We are also grateful to the experts who participated in the questionnaire survey. Additionally, we acknowledge that the research methodology reported in this paper is similar to that of other papers developed and published from the international survey, but with different samples for analyses and hence results. The authors' special thanks also go to the editors and anonymous reviewers who provided invaluable comments and suggestions for honing the quality of this paper.

Author Contributions: This paper was developed as part of Amos Darko's Ph.D. study, which provided the originality. While Amos Darko wrote the paper, as his Ph.D. supervisor, Albert Ping Chuen Chan stimulated the research idea and advised on the structure and presentation of the paper, providing feedback for improving initial drafts of the paper. Ernest Effah Ameyaw contributed to designing the questionnaire for the international survey, and provided feedback for improving initial drafts of the paper.

Conflicts of Interest: The authors declare no conflict of interest.

\section{Appendix A}

Table A1. Relevant section of the questionnaire.

\begin{tabular}{ccc}
\hline Code & Strategies for Promoting GBTs Adoption & Level of Importance \\
\hline P01 & Financial and further market-based incentives for GBTs adopters & 12345 \\
P02 & Mandatory governmental policies and regulations & 12345 \\
P03 & Green rating and labeling & 12345 \\
P04 & Better enforcement of existing green building policies and standards & 12345 \\
P05 & Low-cost loans and subsidy from government \\
P06 & Public environmental awareness creation through workshops, seminars, & 12345 \\
and conferences & 12345 \\
P07 & More publicity through media (e.g., print media, internet, and radio and \\
& television programs) & 12345 \\
P08 & Educational programs for developers, contractors, and policy makers & \\
P09 & related to GBTs & 12345 \\
P10 & Availability of better information on cost and benefits of GBTs & 12345 \\
P11 & Availability of institutional framework for effective implementation of GBTs & 12345 \\
P12 & A strengthened GBTs research and communication & 12345 \\
\hline
\end{tabular}

Note: Experts assessed these strategies on a scale from 1 (not important) to 5 (very important). 


\section{References}

1. Geng, X.; Wen, Y.; Zhou, C.; Xiao, C. Establishment of the sustainable ecosystem for the regional shipping industry based on system dynamics sustainability. Sustainability 2017, 9, 742. [CrossRef]

2. Yudelson, J. Green Building A to Z: Understanding the Language of Green Building; New Society Publishers: Gabriola Island, BC, Canada, 2007.

3. UNEP. Sustainable Buildings and Climate Initiatives. 2011. Available online: http://www.unep.org/sbci/ pdfs/sbci_2pager_eversion_Feb2011.pdf (accessed on 27 March 2017).

4. World Business Council for Sustainable Development. Collaborative Action for Energy Regional Network Case Study: Hong Kong BEAM: Green Building Label. 2008. Available online: http:/ / oldwww.wbcsd.org/ DocRoot/EDlu2NXcBSMEJrKtBKHJ/hk-beam.pdf (accessed on 14 April 2015).

5. Sev, A. How can the construction industry contribute to sustainable development? A conceptual framework. Sustain. Dev. 2009, 17, 161-173. [CrossRef]

6. Son, H.; Kim, C.; Chong, W.K.; Chou, J.S. Implementing sustainable development in the construction industry: Constructors' perspectives in the US and Korea. Sustain. Dev. 2011, 19, 337-347. [CrossRef]

7. United States Environmental Protection Agency. Definition of Green Building. 2016. Available online: https:/ / archive.epa.gov/greenbuilding/web/html/about.html (accessed on 28 March 2017).

8. Hwang, B.G.; Zhu, L.; Tan, J.S.H. Green business park project management: Barriers and solutions for sustainable development. J. Clean. Prod. 2017, 153, 209-219. [CrossRef]

9. Construction, M.H. World Green Building Trends: Business Benefits Driving New and Retrofit Market Opportunities in Over 60 Countries; McGraw-Hill Construction: Bedford, UK, 2013.

10. Ahmad, T.; Thaheem, M.J.; Anwar, A. Developing a green-building design approach by selective use of systems and techniques. Archit. Eng. Des. Manag. 2016, 12, 29-50. [CrossRef]

11. Zhang, X.; Platten, A.; Shen, L. Green property development practice in China: Costs and barriers. Build. Environ. 2011, 46, 2153-2160. [CrossRef]

12. Zhang, X.; Shen, L.; Wu, Y. Green strategy for gaining competitive advantage in housing development: A China study. J. Clean. Prod. 2011, 19, 157-167. [CrossRef]

13. Hoffman, A.J.; Henn, R. Overcoming the social and psychological barriers to green building. Organ. Environ. 2008, 21, 390-419. [CrossRef]

14. Balaras, C.A.; Gaglia, A.G.; Georgopoulou, E.; Mirasgedis, S.; Sarafidis, Y.; Lalas, D.P. European residential buildings and empirical assessment of the Hellenic building stock, energy consumption, emissions and potential energy savings. Build. Environ. 2007, 42, 1298-1314. [CrossRef]

15. Galante, A.; Pasetti, G. A methodology for evaluating the potential energy savings of retrofitting residential building stocks. Sustain. Cities Soc. 2012, 4, 12-21.

16. Zhang, X.; Shen, L.; Wu, Y.; Qi, G. Barriers to implement green strategy in the process of developing real estate projects. Open Waste Manag. J. 2011, 4, 33-37.

17. Qian, Q.K.; Chan, E.H.W.; Khalid, A.G. Challenges in delivering green building projects: Unearthing the transaction costs (TCs). Sustainability 2015, 7, 3615-3636. [CrossRef]

18. Chan, A.P.C.; Darko, A.; Ameyaw, E.E.; Owusu-Manu, D.G. Barriers affecting the adoption of green building technologies. J. Manag. Eng. 2016, 33. [CrossRef]

19. Hwang, B.G.; Tan, J.S. Green building project management: Obstacles and solutions for sustainable development. Sustain. Dev. 2012, 20, 335-349. [CrossRef]

20. Wong, J.K.W.; Chan, J.K.S.; Wadu, M.J. Facilitating effective green procurement in construction projects: An empirical study of the enablers. J. Clean. Prod. 2016, 135, 859-871. [CrossRef]

21. Darko, A.; Chan, A.P.C.; Ameyaw, E.E.; He, B.J.; Olanipekun, A.O. Examining issues influencing green building technologies adoption: The United States green building experts' perspectives. Energy Build. 2017, 144, 320-332. [CrossRef]

22. Darko, A.; Chan, A.P.C.; Owusu-Manu, D.G.; Ameyaw, E.E. Drivers for implementing green building technologies: An international survey of experts. J. Clean. Prod. 2017, 145, 386-394. [CrossRef]

23. Qian, Q.K.; Chan, E.H.W. Government measures for promoting building energy efficiency (BEE): A comparative study between China and some developed countries. In Proceedings of the CRIOCM2007 International Symposium on Advancement of Construction Management and Real Estate, Sydney, Australia, 9-13 August 2007. 
24. Potbhare, V.; Syal, M.; Korkmaz, S. Adoption of green building guidelines in developing countries based on US and India experiences. J. Green Build. 2009, 4, 158-174. [CrossRef]

25. Li, Y.; Yang, L.; He, B.; Zhao, D. Green building in China: Needs great promotion. Sustain. Cities Soc. 2014, 11, 1-6. [CrossRef]

26. Qian, Q.K.; Chan, E.H. Government measures needed to promote building energy efficiency (BEE) in China. Facilities 2010, 28, 564-589. [CrossRef]

27. Windapo, A.O. Examination of green building drivers in the South African construction industry: Economics versus ecology. Sustainability 2014, 6, 6088-6106. [CrossRef]

28. Zhang, X. Green real estate development in China: State of art and prospect agenda-A review. Renew. Sustain. Energy Rev. 2015, 47, 1-13. [CrossRef]

29. Murtagh, N.; Roberts, A.; Hind, R. The relationship between motivations of architectural designers and environmentally sustainable construction design. Constr. Manag. Econ. 2016, 34, 61-75. [CrossRef]

30. Chan, E.H.W.; Qian, Q.K.; Lam, P.T.I. The market for green building in developed Asian cities-The perspectives of building designers. Energy Policy 2009, 37, 3061-3070. [CrossRef]

31. Olubunmi, O.A.; Xia, P.B.; Skitmore, M. Green building incentives: A review. Renew. Sustain. Energy Rev. 2016, 59, 1611-1621. [CrossRef]

32. Qian, Q.K.; Fan, K.; Chan, E.H. Regulatory incentives for green buildings: Gross floor area concessions. Build. Res. Inf. 2016, 44, 675-693. [CrossRef]

33. Shazmin, S.A.A.; Sipan, I.; Sapri, M. Property tax assessment incentives for green building: A review. Renew. Sustain. Energy Rev. 2016, 60, 536-548. [CrossRef]

34. Häkkinen, T.; Belloni, K. Barriers and drivers for sustainable building. Build. Res. Inf. 2011, 39, 239-255. [CrossRef]

35. Zhao, D.X.; He, B.J.; Johnson, C.; Mou, B. Social problems of green buildings: From the humanistic needs to social acceptance. Renew. Sustain. Energy Rev. 2015, 51, 1594-1609. [CrossRef]

36. Darko, A.; Zhang, C.; Chan, A.P.C. Drivers for green building: A review of empirical studies. Habitat Int. 2017, 60, 34-49. [CrossRef]

37. Yang, W.; Zhang, Y. Research on factors of green purchasing practices of Chinese. J. Bus. Manag. Econ. 2012, 3, 222-231.

38. Lam, P.T.; Chan, E.H.; Chau, C.K.; Poon, C.S.; Chun, K.P. Integrating green specifications in construction and overcoming barriers in their use. J. Prof. Issues Eng. Educ. Pract. 2009, 135, 142-152. [CrossRef]

39. Li, Y.; Chen, X.; Wang, X.; Xu, Y.; Chen, P.H. A review of studies on green building assessment methods by comparative analysis. Energy Build. 2007, 146, 152-159. [CrossRef]

40. Shi, Q.; Zuo, J.; Huang, R.; Huang, J.; Pullen, S. Identifying the critical factors for green construction-An empirical study in China. Habitat Int. 2013, 40,1-8. [CrossRef]

41. Gou, Z.; Lau, S.S.Y.; Prasad, D. Market readiness and policy implications for green buildings: Case study from Hong Kong. J. Green Build. 2013, 8, 162-173. [CrossRef]

42. Mulligan, T.D.; Mollaoglu-Korkmaz, S.; Cotner, R.; Goldsberry, A.D. Public policy and impacts on adoption of sustainable built environments: Learning from the construction industry playmakers. J. Green Build. 2014, 9, 182-202. [CrossRef]

43. Shen, L.; Zhang, Z.; Zhang, X. Key factors affecting green procurement in real estate development: A China study. J. Clean. Prod. 2016, 153, 372-383. [CrossRef]

44. Gan, X.; Zuo, J.; Ye, K.; Skitmore, M.; Xiong, B. Why sustainable construction? Why not? An owner's perspective. Habitat Int. 2015, 47, 61-68. [CrossRef]

45. Van Doren, D.; Giezen, M.; Driessen, P.P.J.; Runhaar, H.A.C. Scaling-up energy conservation initiatives: Barriers and local strategies. Sustain. Cities Soc. 2016, 26, 227-239. [CrossRef]

46. Tan, W.C.K. Practical Research Methods; Pearson Custom: Singapore, 2011.

47. Xue, F.; Gou, Z.; Lau, S.S.Y. Human factors in green office building design: The impact of workplace green features on health perceptions in high-rise high-density Asian cities. Sustainability 2016, 8, 1095. [CrossRef]

48. Zhu, Y.; Ding, J.; Zhu, Q.; Cheng, Y.; Ma, Q.; Ji, X. The impact of green open space on community attachment-A case study of three communities in Beijing. Sustainability 2017, 9, 560. [CrossRef]

49. Ackroyd, S.; Hughes, J.A. Data Collection in Context; Longman: London, UK, 1981.

50. Ekanayake, L.L.; Ofori, G. Building waste assessment score: Design-based tool. Build. Environ. 2004, 39, 851-861. [CrossRef] 
51. Hwang, B.G.; Zhu, L.; Ming, J.T.T. Factors affecting productivity in green building construction projects: The case of Singapore. J. Manag. Eng. 2016, 33. [CrossRef]

52. Cabaniss, K. Computer-related technology use by counselors in the new millennium: A Delphi study. J. Technol. Couns. 2002, 2, 3-34.

53. Tongco, M.D.C. Purposive Sampling as a Tool for Informant Selection. 2007. Available online: http: / / hdl.handle.net/10125/227 (accessed on 1 June 2017).

54. Hodges, N. Qualitative research: A discussion of frequently articulated qualms (FAQs). Fam. Consum. Sci. Res. J. 2011, 40, 90-92. [CrossRef]

55. Smith, J.; Noble, H. Bias in research. Evid. Based Nurs. 2014, 17, 100-101. [CrossRef] [PubMed]

56. Beeken, R.J.; Croker, H.; Morris, S.; Leurent, B.; Omar, R.; Nazareth, I.; Wardle, J. Study protocol for the 10 Top Tips (10TT) Trial: Randomised controlled trial of habit-based advice for weight control in general practice. BMC Public Health 2012, 12, 667. [CrossRef] [PubMed]

57. Li, Y.Y.; Chen, P.H.; Chew, D.A.S.; Teo, C.C.; Ding, R.G. Critical project management factors of AEC firms for delivering green building projects in Singapore. J. Constr. Eng. Manag. 2011, 137, 1153-1163. [CrossRef]

58. Cheng, E.W.L.; Li, H. Construction partnering process and associated critical success factors: Quantitative investigation. J. Manag. Eng. 2002, 18, 194-202. [CrossRef]

59. Rahman, M.M. Barriers of implementing modern methods of construction. J. Manag. Eng. 2014, 30, 69-77. [CrossRef]

60. Ott, R.L.; Longnecker, M. An Introduction to Statistical Methods and Data Analysis; Brooks/Cole, Cengage Learning: Belmont, CA, USA, 2010.

61. Zhao, X.; Hwang, B.G.; Lee, H.N. Identifying critical leadership styles of project managers for green building projects. Int. J. Constr. Manag. 2016, 16, 150-160. [CrossRef]

62. Choi, T.N.Y. Investigating the Current Application and Exploring the Future Development of Pay for Safety Scheme (PFSS) in Hong Kong Construction Industry. Ph.D. Thesis, Hong Kong Polytechnic University, Hong Kong, China, 2012.

63. Santos, J.R.A. Cronbach's alpha: A tool for assessing the reliability of scales. J. Ext. 1999, 37, 1-5.

64. Chan, A.P.C.; Chan, D.W.M.; Chiang, Y.H.; Tang, B.S.; Chan, E.H.W.; Ho, K.S. Exploring critical success factors for partnering in construction projects. J. Constr. Eng. Manag. 2004, 130, 188-198. [CrossRef]

65. Chan, A.P.C.; Lam, P.T.I.; Chan, D.W.M.; Cheung, E.; Ke, Y. Critical success factors for PPPs in infrastructure developments: Chinese perspective. J. Constr. Eng. Manag. 2010, 136, 484-494. [CrossRef]

66. Siegel, S.; Castellan, N.J. Nonparametric Statistics for the Behavioral Sciences, 2nd ed.; McGraw-Hill: New York, NY, USA, 1988.

67. Lam, P.T.; Chan, E.H.; Ann, T.W.; Cam, W.C.; Jack, S.Y. Applicability of clean development mechanism to the Hong Kong building sector. J. Clean. Prod. 2015, 109, 271-283. [CrossRef]

68. Pallant, J. SPSS Survival Manual: A Step by Step Guide to Data Analysis Using the SPSS Program; Allen \& Unwin: Sydney, Australia, 2011.

69. Norusis, M.J. IBM SPSS Statistics 19. Guide to Data Analysis; Addison Wesley: Boston, MA, USA, 2011.

70. Glenn, E.S.; Glenn, C.G. Man and Mankind; Ablex Pub. Corp.: New York, NY, USA, 1981.

71. Cheng, E.W.L.; Li, H. Development of a conceptual model of construction partnering. Eng. Constr. Archit. Manag. 2001, 8, 292-303. [CrossRef]

72. Maxwell, E.; Foley, M.; Braman, J.; Sopeth, J.; Marty, R. Rosemount Eco-Green Business Park Feasibility Study; University of Minnesota: Minneapolis, MN, USA, 2015.

73. Azis, S.S.A.; Sipan, I.; Sapri, M. The potential of implementing property tax incentives on green building in Malaysia. Am. J. Econ. 2013, 3, 63-67.

74. USGBC. Building Momentum: National Trends and Prospects for High Performance Green Buildings; U.S. Green Building Council: Washington, DC, USA, 2003.

75. Kibert, C.J. Sustainable Construction: Green Building Design and Delivery; John Wiley \& Sons: Hoboken, NJ, USA, 2008.

76. Ali, H.H.; Al Nsairat, S.F. Developing a green building assessment tool for developing countries-Case of Jordan. Build. Environ. 2009, 44, 1053-1064. [CrossRef]

77. Ofori, G.; Ho, L.K. Translating Singapore architects' environmental awareness into decision making. Build. Res. Inf. 2004, 32, 27-37. [CrossRef] 
78. Building and Construction Authority. 2nd Green Building Masterplan. 2009. Available online: http: //www.bca.gov.sg/greenMark/others/gbmp2.pdf (accessed on 18 October 2014).

79. Zuo, J.; Zhao, Z.Y. Green building research-Current status and future agenda: A review. Renew. Sustain. Energy Rev. 2014, 30, 271-281. [CrossRef] 